\begin{tabular}{|c|l|}
\hline Title & ON THE PREPARA TION OF ISOTOPICA LLY PURE LIGHT HYDROGEN \\
\hline Author(s) & MIYAHARA, Koshiro; KWA N, Takao \\
\hline Citation & JOURNAL OF THE RESEARCH INSTITUTE FOR CA TALY SIS HOKKA IDO UNIVERSITY, 7(1), 77-78 \\
\hline Issue Date & 1959-09 \\
\hline Doc URL & http://hdl.handle.net/2115/24697 \\
\hline Type & bulletin (article) \\
\hline File Information & 7(1)_P77-78.pdf \\
\hline
\end{tabular}

Instructions for use 
Short Notes

\title{
ON THE PREPARATION OF ISOTOPICALLY PURE LIGHT HYDROGEN
}

\author{
By Koshiro Miyahara and Takao Kwan*)
}

(Received July 30, 1959)

Natural abundance of heavy hydrogen isotope in the water is known to vary depending on the geochemical circumstances in whicl the water is found. ${ }^{11}$ The standardization of the value of D-content in the water or the preparation of isotopically pure light hydrogen was thus needed and became the object of careful investigation particularly by TITANI and his coworkers. ${ }^{2,3)}$ Electrolysis of water is known to produce hydrogen of less D-content. Combustion of the hydrogen followed by re-electrolysis leads to much less concentration in the heavy component. Repeating such procedure, these authors were able to obtain 125 gram light water, the atomic $\mathrm{D} \%$ of which being $0.0002 \pm 0.00004$, i.e., about one-hundredth of natural abundance.

Current investigation on the chromatography, on the other hand, showed that this technique is powerful for the separation of hydrogen isotopes. Glueckauf and $\operatorname{KITT}^{4}$ were able to isolate pure deuterıum $(99.5 \%)$ from a mixture of hydrogen isotopes by a displacement technique using palladium as column packing. The work $^{5)}$ of this laboratory proved that hydrogen isotopes are separated in the elution chromatogram when synthetic zeolite (Linde molecular sieve) is used as column packing and kept at $-195^{\circ} \mathrm{C}$.

Deuterium was found to adsorb strongly compared with ordinary hydrogen on this packing ${ }^{4 a)}$. As a result, self-displacement of a mixture of hydrogen isotopes through such a cooled column yielded pure hydrogen in the frontal band and then $\mathrm{HD}$ and $\mathrm{D}_{z}$ in the succeeding band respectively. ${ }^{5)}$ The detection of these hydrogen isotopes were made in this case by the thermal conductivity gauge equipped in Shimadzu Gas Chromatograph GC 1A, the sensitivity of which was estimated at

*) K. M. and T. K. : Research Institute for Catalysis, Hokkaido University.

1) M. Harada and T. Titani, Bull. Chem. Soc. Japan 10, 206, 263 (1935).

G. R. ClARKE, Nature 174, 469 (1954).

2) T. Titani, S. HoRIBE and M. KOBAyaKaWA, Mass Spectroseopy 9, 32 (1957) (in Japanese).

3) T. TITANI, S. HoRIBE, T. KOMORI and M. KoBAyaKaWA, Mass Spectroscopy 9, 40 (1957) (in Japanese).

4) E. Glueckauf and G. P. KITT, Vapour Phase Chromatography, p. 422 (1957) Butterworths Scientific Publications, London.

4 a) S. FURUYAMA and T. KWAN, to be published.

5) S. Ohkoshi, Y. Fujita and T. Kwan, Bull. Chem. Soc. Japan 31, 771775 (1958). 
the highest as $1.0 \mathrm{D}$-atomic $\%$ for $10 \mathrm{cc} \mathrm{N.T.P.} \mathrm{hydrogen} \mathrm{sample.}$

It is obvious however that the latter technique is promising to obtain isotopically pure light hydrogen. An attempt was made therefore to investigate the isolation of light component from ordinary hydrogen by means of such chromatographic technique, and in particular to detect hydrogen isotopes by much more sensitive instrument such as mass spectrometer in place of thermal conductivity gauge. A spiral Pyrex column $400 \mathrm{~cm}$ long and $0.5 \mathrm{~cm}$ diameter was filled with molecular sieve $5 \mathrm{~A}$ and degassed over night at $300^{\circ} \mathrm{C}$ by mercury diffusion pump. Two liters hydrogen sample from commercial electrolytic hydrogen ${ }^{*)}$ was introduced into the one side of the column immersed in liquid nitrogen. About ten minutes later hydrogen was found to appear on the other side of the column. The initial portion of the hydrogen (100-200 cc N.T.P.) was then collected in a flask (sample I). The remaining hydrogen, together with those adsorbed on the packing, was collected back to the original flask (sample II). The deuterium content of the two samples was analysed respectively by Hitachi Mass Spectrometer RMD-3. The result is shown in Table 1 below.

TABLE I

\begin{tabular}{c|c|c|c|c}
\hline Run & $\begin{array}{c}\text { Hydrogen } \\
\text { sample }\end{array}$ & $\begin{array}{c}\text { Volume } \\
\text { cc N.T.P. }\end{array}$ & $\begin{array}{c}\text { Atomic } \\
D \%\end{array}$ & $\begin{array}{c}\text { Experimental error } \\
\text { Atomic D \% }\end{array}$ \\
\hline \multirow{2}{*}{1} & I & 100 & 0.0000 & \\
& II & 1900 & 0.0068 & \pm 0.0005 \\
\hline \multirow{2}{*}{2} & I & 200 & 0.0004 & \pm 0.0005 \\
\hline
\end{tabular}

As shown in the table, the sample I was found perfectly freed from heavy component within the accuracy of the mass spectrometer. Thus, it is quite evident that the chromatographic process is simple and efficient to prepare istotopically pure light hydrogen. At the same time, the process is of practical importance to enrich deuterium or tritium at least in laboratory scale ${ }^{5}$ if it is repeated with respect to the sample II.

*) Supplied by Hokkaido Soda Co., Horobetsu, Hokkaido. 